\title{
Biología y Patrimonio Cultural: Estudio de la comunidad de plantas que colonizaban la fachada de la Iglesia de San Pablo (Valladolid)
}

\author{
Manuel García Sáez
}

Resumen: La Biología forma parte del conjunto de ciencias aplicadas al estudio de los agentes de degradación que afectan a los materiales que conforman los bienes culturales, en éste caso las rocas monumentales. A continuación presentamos un ejemplo práctico: el muestreo, identificación, estudio, conclusiones y recomendaciones finales, sobre la comunidad de plantas que colonizaban la fachada de la iglesia de San Pablo de Valladolid. El trabajo formó parte, como un capítulo inicial, de las labores que se llevaron a cabo durante la intervención integral de restauración de la citada portada, un magnífico ejemplo de retablo en piedra del arte gótico español.

Palabras clave: Biología y patrimonio; biodeterioro; plantas superiores colonizadoras; indicadores biológicos de alteración; control y mantenimiento

\section{Biology and Cultural Heritage: Study of plant community colonizing the Saint Paul's Church façade (Valladolid)}

\begin{abstract}
Biology is part of the set of applied sciences to the study of degradation agents that affect materials that make cultural property, in this case the monumental rocks. Here is a case study: sampling, identification; study; conclusions and final recommendations, on plant community colonizing Saint Paul's Church façade in Valladolid. This work was part, as an initial chapter, of the work to be performed during the comprehensive intervention restoration of said cover, a magnificent example of stone altarpiece of Spanish Gothic art.
\end{abstract}

Key words: Biology and heritage; biodeterioration; colonizing higher plants; biological degradation indicators; control and maintenance

\section{Biologia e Património Cultural: Estudo da comunidade de plantas que colonizavam a fachada da igreja de San Pablo ( Valladolid)}

Resumo: A Biología faz parte do conjunto das ciências aplicadas ao estudo dos agentes de degradação que afectam os materiais que constituem os bens culturais, neste caso as pedras dos monumentos. De seguida, apresentamos um exemplo prático: a amostragem, identificação, estudo, conclusões e recomendações finais, sobre a comunidade de plantas que colonizavam a fachada da igreja de San Pablo em Valladolid. Este trabalho forma parte, com o capitulo inicial, dos trabalhos levados a cabo durante a intervenção integral da restauração da citada portada, que constituiu um exemplo raro de arte gótica espanhola de um retábulo em pedra.

Palavras-chave: Biología e do patrimonio; biodeterioraçao; plantas superiores que colonizam; indicadores biológicos de deficiencia; controle e manutençao 


\section{Introducción}

Si consideramos el material que conforma un bien de interés cultural (BIC) cualquiera, ya sea este un bien mueble ó inmueble (una pieza de museo, un edificio histórico-artístico, las piezas de una colección de historia natural, etc.) desde el punto de vista de la Ecología, veremos enseguida que es capaz de servir, como soporte físico, para la colonización de múltiples organismos vivos que, una vez establecidos en espacio y tiempo constituirán, sin duda, un ecosistema adaptado y característico al objeto cultural y su composición material específica (orgánica, inorgánica ó ambas).

Las rocas monumentales, al estar sometidas a los agentes atmosféricos y sus contaminantes, son especialmente susceptibles a los factores causantes de biodeterioro por constituirse como óptimos substratos de crecimiento (alta bioreceptividad) para los organismos vivos, y en concreto, a los del reino vegetal: algas, líquenes, briofitos (musgos, hepáticas) y plantas vasculares ó superiores, en orden de sucesión vegetal en el tiempo. Así, en su conjunto, el monumento se presenta como un ecosistema singular en el que una notable diversidad de especies de flora ( $y$ fauna también por supuesto) desarrollan sus ciclos vitales en función del entorno (luz solar, orientación, climatología local, microclima del monumento, agua, polución del aire, y otros factores), estableciéndose comunidades de poblaciones que interactúan entre sí y con el substrato que las sustenta: nutrientes orgánicos e inorgánicos presentes en la piedra, ya sea en su interior ó en su superficie ("biofilm").

La mayor parte de los estudios referidos a especies vegetales como agentes de alteración de los materiales constituyentes de bienes culturales inmuebles se han centrado en los grupos botánicos denominados "inferiores" (algas, líquenes, briofitos), siendo más escasa la bibliografía acerca del grupo de las plantas "superiores", casi siempre enfocada a la colonización de estas especies vegetales en los yacimientos arqueológicos y sus efectos sobre los bienes allí conservados. La información sobre la presencia y efectos de las plantas vasculares que crecen en edificios y monumentos históricos es escasa y así, éste trabajo pretende contribuir a su conocimiento como agentes de alteración y su papel como indicadores de biodeterioro, haciendo hincapié en las sustancias químicas singulares producidas por la actividad metabólica de cada especie durante su ciclo biológico.

El presente estudio, que data del año 2007, da cuenta del trabajo de identificación, análisis y tratamiento de la comunidad de plantas superiores encontrada en la fachada principal (de estilo gótico) de la iglesia de San Pablo de Valladolid, enmarcado dentro del plan general de la intervención de restauración y conservación integral que se llevó a cabo en éste BIC a lo largo de dicho año.

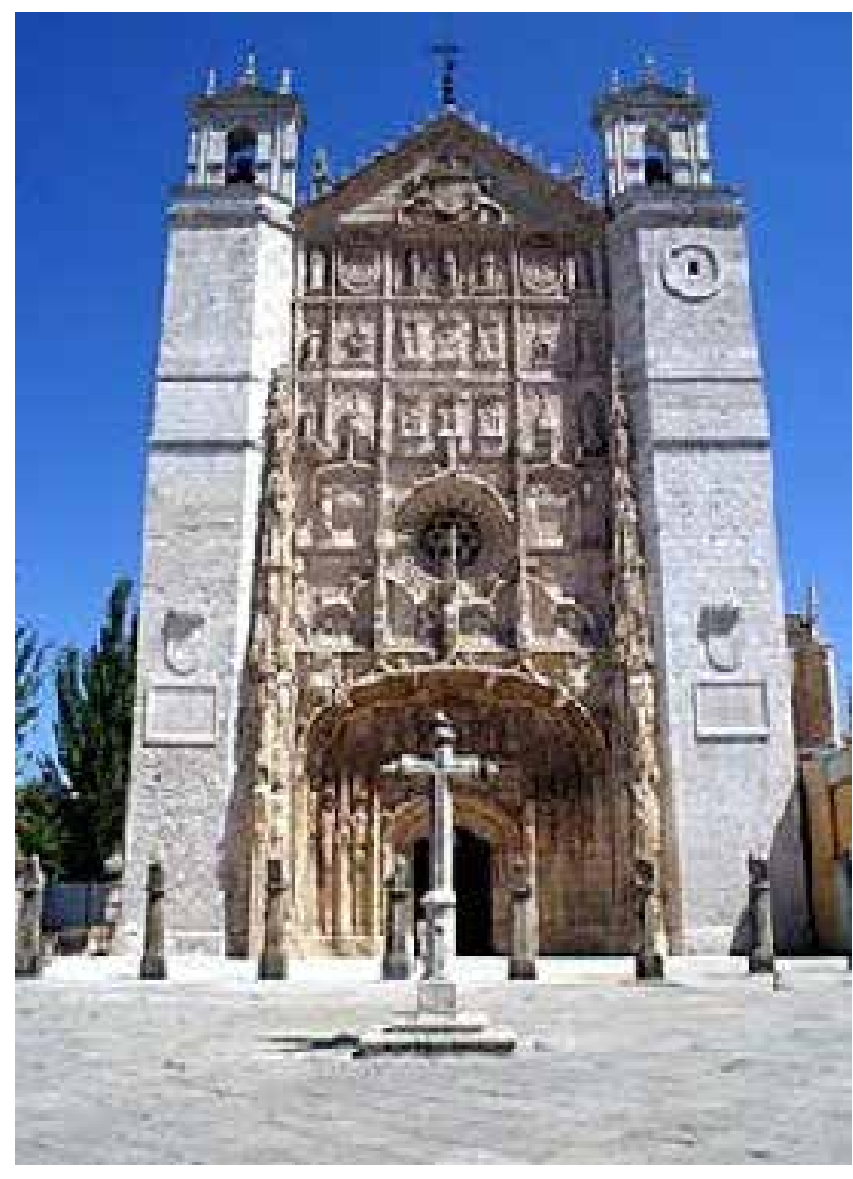

Figura 1.- Imagen de la fachada de San Pablo tras su restauración

\section{Recolección de muestras}

En el mes de mayo del año 2007, se visitó la obra "in situ" para llevar a cabo el trabajo de campo durante toda una jornada. Esta época de finales de primavera era la idónea para las labores de extracción y estudio de ejemplares, puesto que las especies conservan sus flores y/ó semillas y por tanto facilitan al máximo la tarea de identificación y reconocimiento taxonómico de las especies. A lo largo de la jornada de trabajo se realizaron las tareas de recolección de muestras para su posterior identificación. A su vez, se hicieron las anotaciones particulares que se creyeron necesarias para apoyar la labor posterior de clasificación en laboratorio-taller: orientación, tipo de crecimiento, condiciones del substrato, etc.

En el transcurso del muestreo se dejó constancia del lugar de recogida de cada ejemplar recolectado, anotando su ubicación en un plano de alzado de la fachada, referenciándola a su vez con el piso de andamio correspondiente. Esto nos permite saber en todo momento la altura en la que nos encontramos, tanto nosotros como las plantas que crecen en cualquier lugar del monumento (cada piso de andamio son módulos de 2 metros de altura).

También se tomaron imágenes fotográficas en soporte 
digital durante la prospección de la fachada, recorriendo sucesivamente todos los pisos del andamiaje de trabajo instalado, desde la planta más alta del mismo (piso 16, a 32 mts. de altura) hacia abajo, hasta el nivel de calle (cota 0$)$.

Las plantas recogidas en fresco se preparaban provisionalmente para el transporte depositándolas en hojas de papel de periódico y, posteriormente, eran colocadas entre dos cartones de embalaje a modo de sándwich. Finalmente cada paquete así elaborado se prensaba manualmente y se ataba con cintas de tela, quedando listo para su traslado.

A continuación se expone el plano con la localización de los puntos de muestreo y las especies recolectadas en los mismos.

\section{Descripción taxonomica de especies. Abundancia relativa y mapa de distribución en la fachada}

Una vez efectuada la toma de muestras y su traslado a estudio, se conservan todos los ejemplares mediante prensado (en prensas de herbario) de las plantas envueltas en papel absorbente durante dos semanas, tras lo que se procede a realizar la labor de análisis taxonómico del material recogido. Para ello, utilizamos las claves

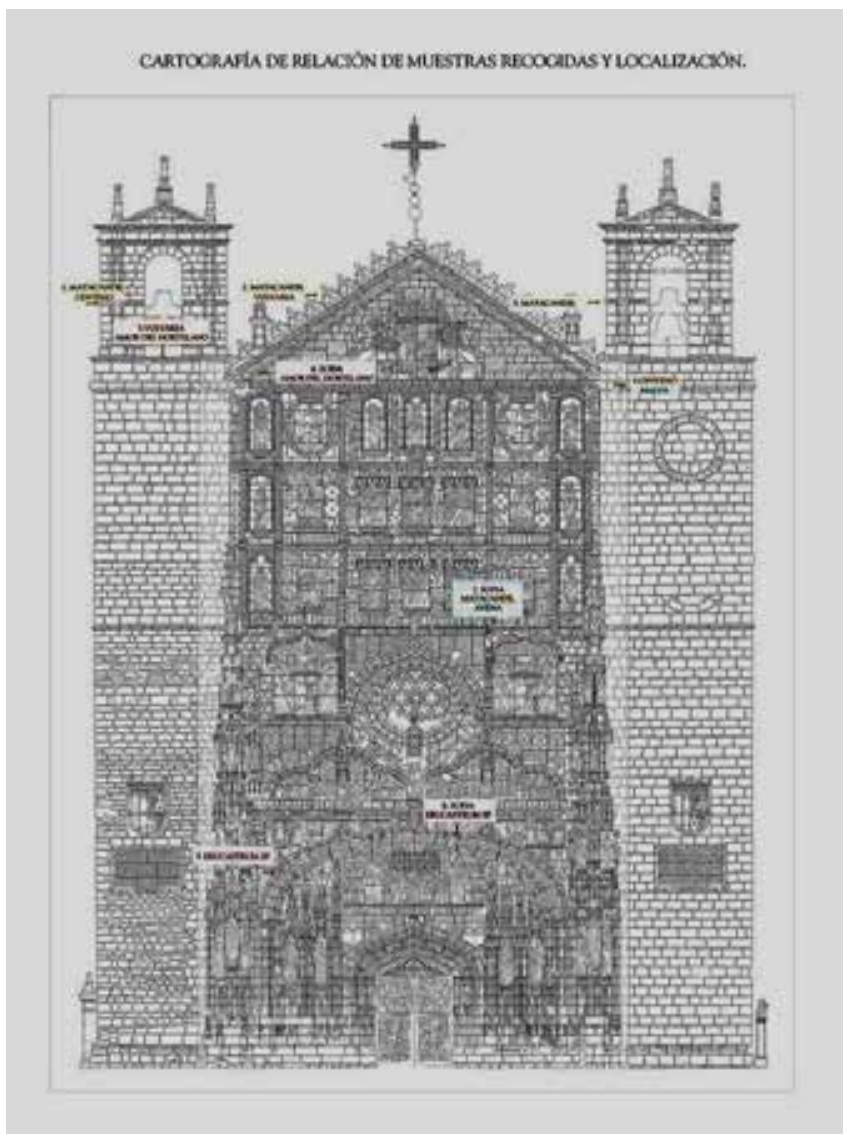

Figura 2.- Cartografía del muestreo dicotómicas que se hallan en las publicaciones científicas especializadas en la materia (Sistemática y Taxonomía Botánicas. Ver bibliografía.), ayudándonos de una lupa binocular (10x50), herramienta imprescindible para abordar éstos menesteres.

A continuación se ofrece el cuadro sinóptico de clasificación de especies de la fachada. Posteriormente, haremos el comentario descriptivo de cada una de ellas. En total se han encontrado 8 especies, englobadas en 5 familias diferentes.

\begin{tabular}{|c|c|c|c|}
\hline \multicolumn{4}{|c|}{$\begin{array}{l}\text { PLANTAS VASCULARES } \\
\text { (ESPERMATOFITOS) }\end{array}$} \\
\hline & FAMILIA & GÉNERO & ESPECIE \\
\hline 1 & $\begin{array}{l}\text { AMARANTÁCEAS } \\
\text { (QUENOPODIEAS) }\end{array}$ & CHENOPODIUM & $\mathrm{CH}$. vulvaria \\
\hline 2 & $\begin{array}{c}\text { POÁCEAS } \\
\text { (GRAMÍNEAS) }\end{array}$ & $\begin{array}{l}\text { SECALE } \\
\text { AVENA }\end{array}$ & $\begin{array}{l}\text { S. cereale } \\
\text { A. sativa }\end{array}$ \\
\hline 3 & MALVÁCEAS & MALVA & M. neglecta \\
\hline 4 & $\begin{array}{l}\text { BRASICÁCEAS } \\
\text { (CRUCÍFERAS) }\end{array}$ & $\begin{array}{l}\text { SISYMBRIUM } \\
\text { ERUCASTRUM } \\
\text { DESCURAINA }\end{array}$ & $\begin{array}{l}\text { S. irio } \\
\text { E. nasturtiifolium } \\
\text { D. sophia }\end{array}$ \\
\hline 5 & RUBIÁCEAS & GALIUM & G. aparine \\
\hline
\end{tabular}

Tabla 1.- Taxonomía de especies recolectadas

\section{QUENOPODIACEAS}

- Chenopodium vulvaria L. (Cast.: Vulvaria. "Cenizo hediondo". "Meaperros")

La vulvaria es una hierba anual de hasta $60 \mathrm{cms}$. de altura, de tallos y hojas como enharinados. Estas últimas tienen un contorno entre aovado y romboidal, con bordes enteros. Sus flores son muy pequeñas, verdegrises, creciendo aglomeradas en las axilas de los tallos. Toda la planta despide un fétido olor a salmuera (como a pescado podrido), debido a que contiene trimetilamina. Además, también produce otras sustancias químicas como sales de amonio, nitratos, fosfatos, ácido málico y algo de amoníaco libre. Se cría en los pies de muros, junto a los caminos, en los barbechos, pantanos de aguas saladas. Florece de Julio a Septiembre por casi todo el país. 


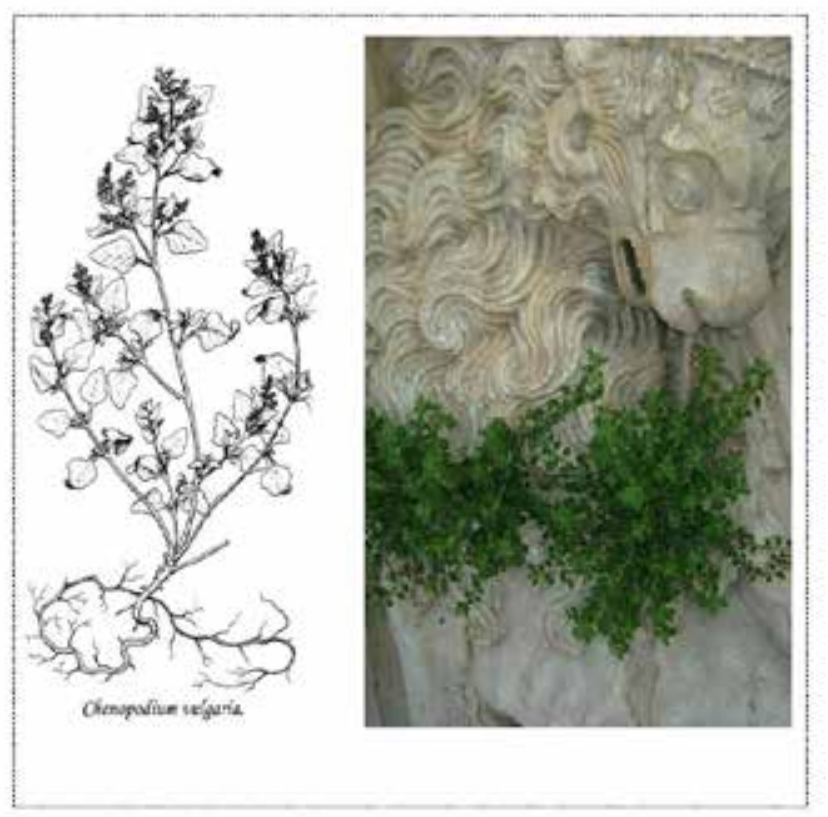

Figura 3.- Vulvaria

\section{POÁCEAS (GRAMÍNEAS)}

\section{- Secale cereale L. (Cast.: Centeno)}

Es una de las especies cerealistas por antonomasia, si bien parece, por los datos aportados por la arqueobotánica, que en la Península Ibérica fue introducida por los romanos, extendiéndose su cultivo por casi toda ella. Se cría de forma ruderal en prácticamente todos los suelos, incluso en los más pobres, y en climas fríos y lluviosos. Posee un sistema radicular fasciculado muy potente, de ahí su rusticidad. Es planta anual.

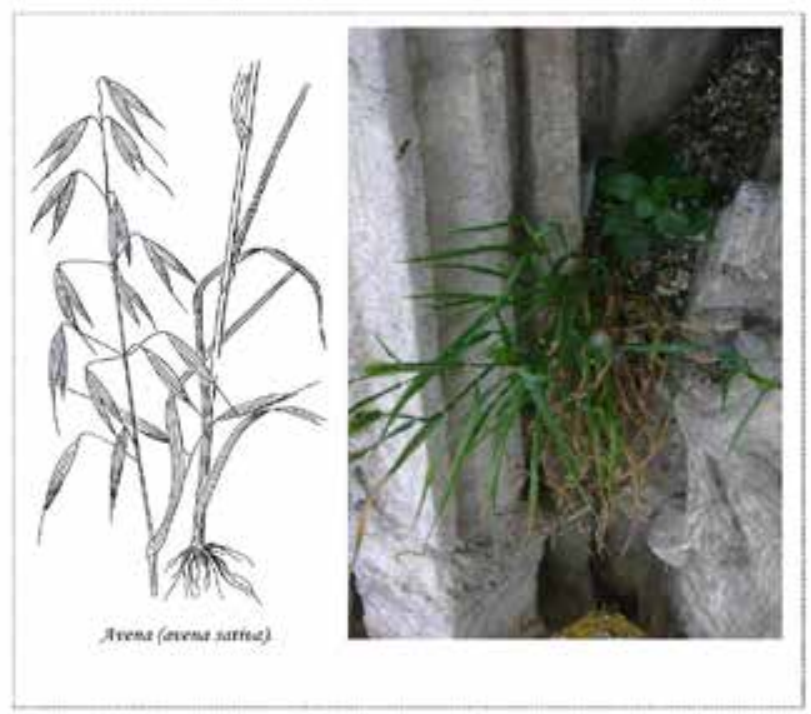

Figura 4.- Avena salvaje

\section{- Avena sativa L. ( Cast.: Avena salvaje)}

Especie cuyo cultivo se remonta a épocas antiguas (Edad del Bronce) en la historia de la humanidad. Al igual que el centeno, se naturaliza con facilidad en suelos no cultivados, si bien necesita que éstos sean algo más ricos en nutrientes, y de climas atemperados en la época de floración. También de ciclo anual.

\section{MALVACEAS.}

- Malva neglecta. (Cast.: Malva enana ó malva rastrera)

Es planta anual, de hasta $60 \mathrm{cms}$. de longitud, con tallos extendidos rastreros (pueden llegar a formar un talo leñoso) y hojas entre arriñonadas y redondeadas, con denso pelo blanco. Soporta bien las heladas. Flores de lila pálido a blanquecinas. Se cría en los márgenes de campos, muros, terrenos removidos, herbazales nitrófilos, descampados urbanos. Florece entre Junio y Septiembre.

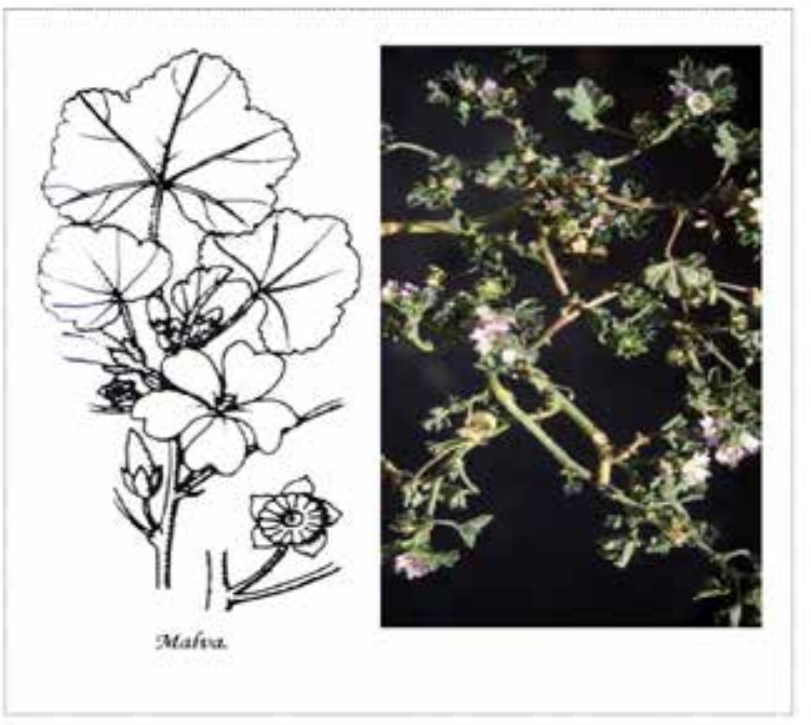

Figura 5.- Malva enana

\section{BRASICÁCEAS (CRUCIFERAS).}

- Sisymbrium irio L. (Cast.: Matacandil)

Planta anual, de entre 20 y $100 \mathrm{cms}$. de altura, erguida y muy poblada de hojas, con tallo simple. Las flores, numerosas, son pequeñas y amarillas, formando ramilletes en el extremo del tallo. Los frutos son vainillas alargadas (hasta 4-5 cms.) que se levantan del tallo, superando el nivel de las flores (rasgo característico de la especie). Florece desde Abril hasta Julio. Se desarrolla en las malas tierras, escombreras, pie de tapias y cercas, así como en los corrales y estercoleros por toda la geografía peninsular. Contiene una esencia sulfurada. 


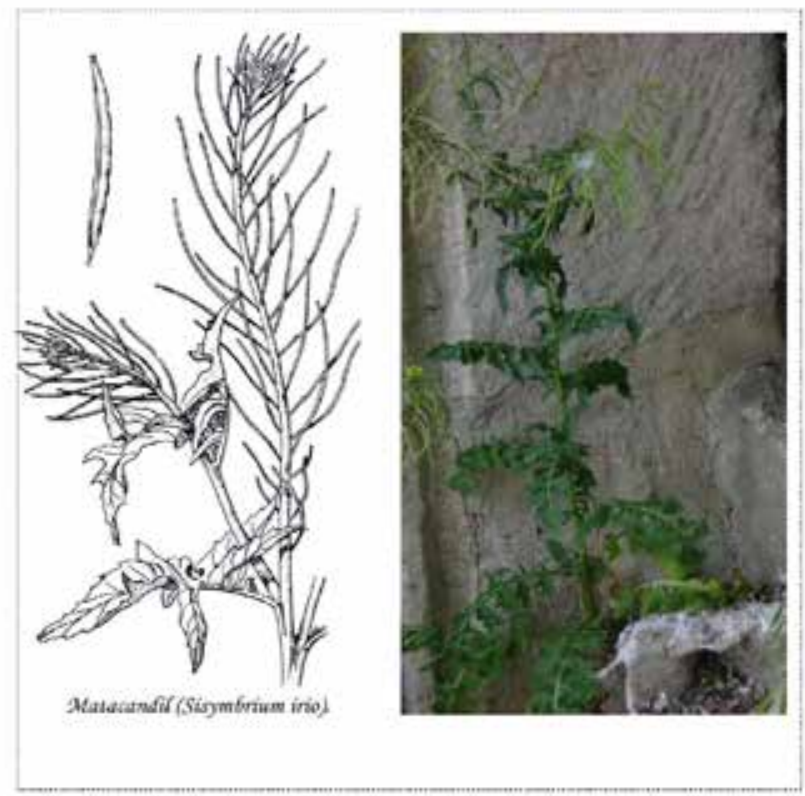

Figura 6.- Matacandil

- Descurainia sophia (Cast: Sofía. Hierba de la sabiduría ó de los cirujanos)

Es una hierba de ciclo anual, de $20-80 \mathrm{cms}$. de altura, con hojas muy divididas. Sus flores son menudas $y$ amarillentas. Los frutos son vainillas finas que se yerguen sobre un cabillo extendido. Florece desde Abril hasta Agosto, criándose en las orillas de los caminos, al pie de muros y cercas, junto escombros y, en suma, no lejos de los caseríos. Se distribuye principalmente en la mitad septentrional de la Península.

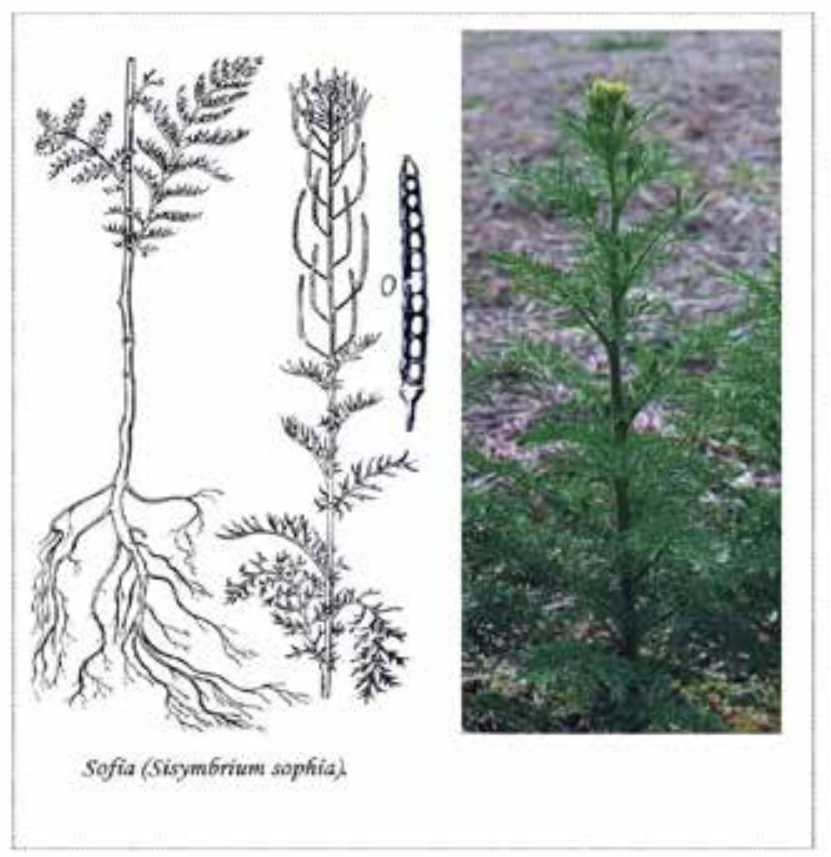

Figura 7.- Sofía

\section{- Erucastrum nasturtiifolium (Cast.: Oruga salvaje)}

Planta bienal de hasta $80 \mathrm{cms}$. de altura, con flores amarillo pálido. Florece de Mayo a Septiembre. Se cría a la vera de caminos, en zonas baldías y medios degradados en general, formando parte del grupo de plantas colonizadoras de rocas y muros calcáreos. Es una especie indicadora de suelos alcalinos, ricos en bases. Soporta bien la sombra y la sequedad del substrato.

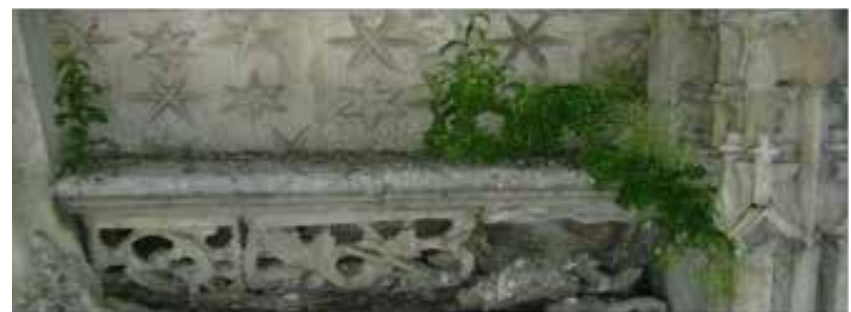

Figura 8.- Oruga salvaje

\section{RUBIACEAS.}

- Galium aparine L. (Cast.: Amor del hortelano).

Planta anual impotente para mantenerse erguida por sí sola, dada la flaccidez de sus tallos cuadrados, los cuáles se alargan desmesuradamente, agarrándose mediante los pequeños pelos ganchudos que posee en ellos a otras plantas vecinas u otros sustentáculos idóneos a tal fin. Esto la permite crecer de modo feraz y desmedido, aún arrancando desde un único punto de enraizamiento. Florece entre primavera y verano, a partir del mes de Mayo. Se cría en setos, márgenes de los huertos y bordes de los senderos de regadíos, siendo por lo tanto amante de medios muy húmedos. Se distribuye por toda España. Contiene sustancias saponificantes y ácidos orgánicos (ácido gálico).

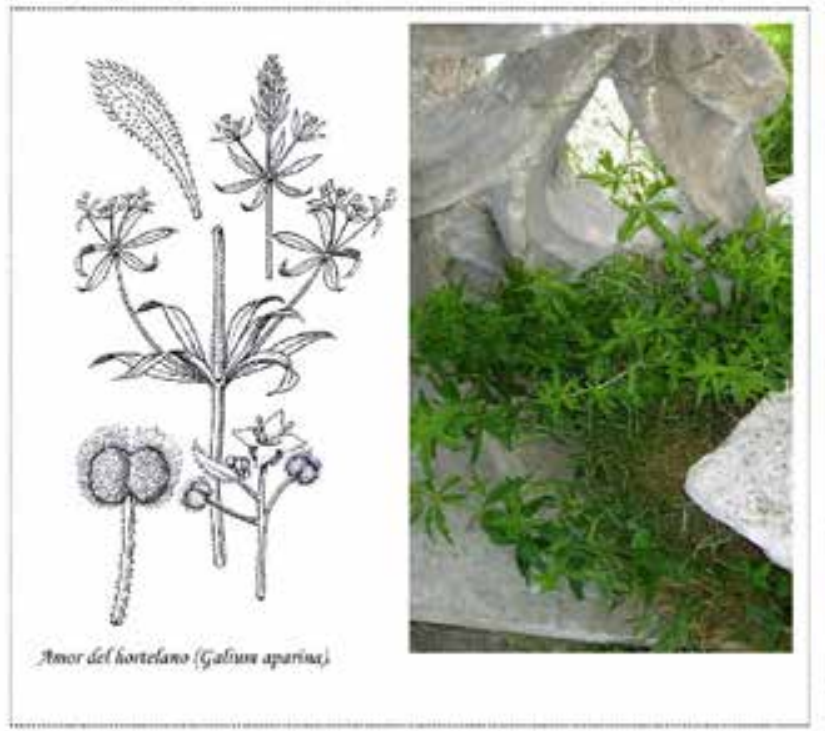

Figura 9.- Amor del hortelano 
CARTOGRAFÍA DE DISTRUBUCIÓN DE ESPECIES EN LA FACHADA.
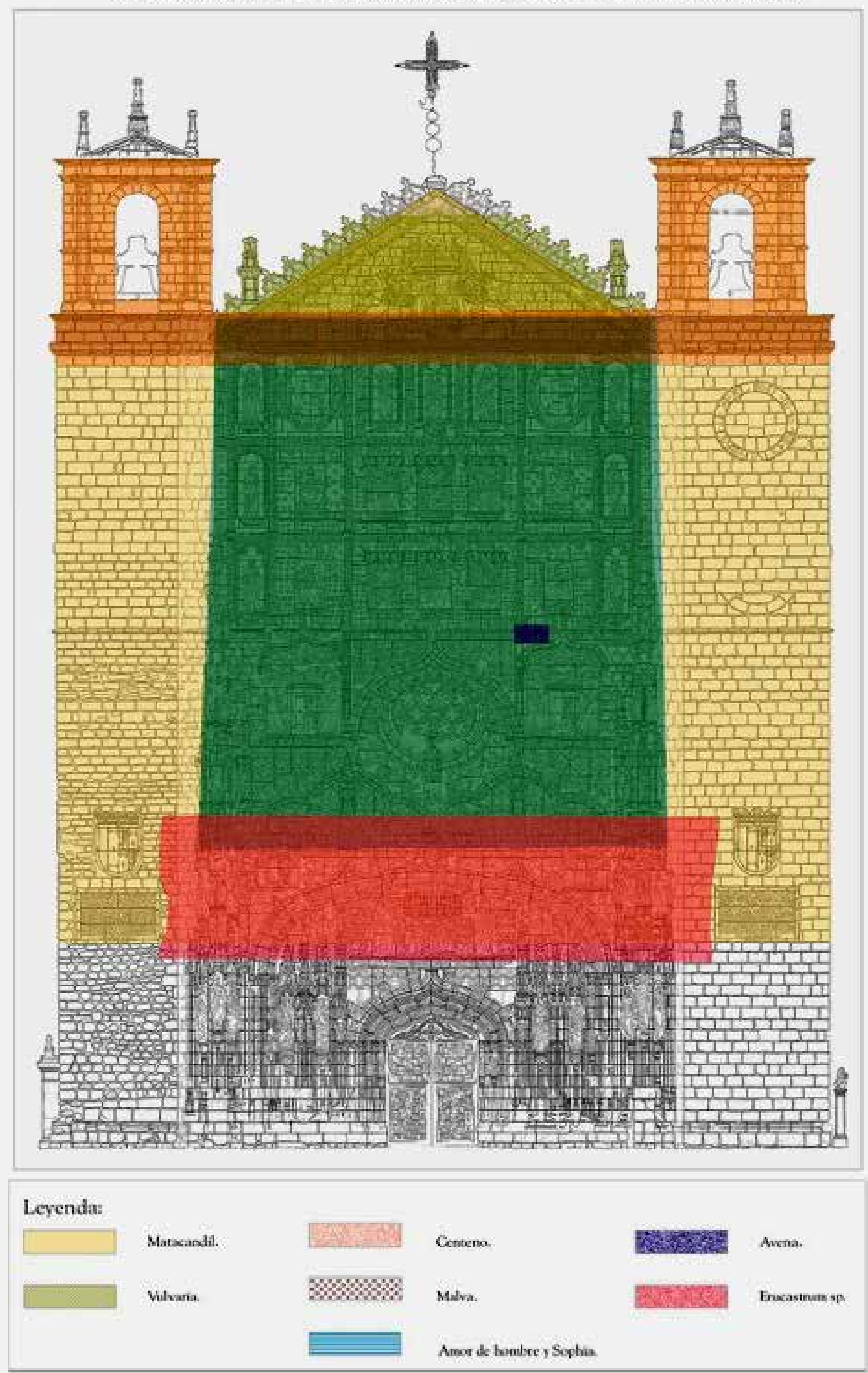

Figura 10.- Cartografía de distribución de especies 
Tras la anterior descripción pormenorizada de especies, podemos concluir que los rasgos característicos de la comunidad de plantas vasculares establecida en la fachada son los siguientes:

a) marcado carácter nitrófilo y ruderal de las poblaciones que forman la comunidad vegetal, es decir son plantas que crecen en substratos ricos en compuestos orgánicos nitrogenados y en medios fuertemente humanizados.

b) son plantas terofíticas (pioneras) formadoras de suelo; herbáceas de ciclo anual ó bianual que pasan el período desfavorable en forma latente (semillas).

c) las especies que la componen prefieren medios de húmedos a muy húmedos.

Respecto a la abundancia relativa de las especies encontradas, hemos de subrayar la preponderancia absoluta de tres de ellas: el matacandil, la vulvaria y el amor del hortelano. Ellas solas suponen el $90 \%$ del total de población de la comunidad vegetal (fitocenosis) establecida en la fachada, si bien hay que señalar que el amor del hortelano medra fundamentalmente en las áreas dónde las otras dos crecen con profusión (sobre todo el matacandil), debido a su peculiar modo de crecimiento, puesto que se apoya en las otras plantas para maximizar su desarrollo.

Las demás especies, salvo el centeno, aparecen esporádica y puntualmente sobre la superficie pétrea. Así por ejemplo, de la avena solamente hemos hallado una única mata en todo el muestreo. Del centeno hay que decir que se desarrolla básicamente en superficies horizontales amplias bien asoleadas, como los solados de piedra de los cuerpos de campanas (en las torres) y cornisas del frontón de remate superior (incluyendo la albardilla posterior), siendo en éstas zonas la planta más abundante junto al matacandil.

En cuanto a la distribución de especies hay que resaltar dos hechos claramente observables: por un lado el predominio generalizado del matacandil colonizando prácticamente cualquier lugar de la obra (torres-campanario y retablo labrado central); y por otro, que la mayor parte de la biomasa vegetal se desarrolla en dos zonas: el tramo superior de la fachada (remates de las torres y frontón), y en las cornisas, arcos y molduras horizontales que se suceden a lo largo de los cuerpos y calles del retablo pétreo esculpido. A destacar, por último, el hecho de que entre el nivel del suelo (cota 0) y la planta $5^{\text {a }}$ del andamio (10 mts. de altura), no encontramos un solo ejemplar de planta creciendo sobre el material lapídeo de la fachada: se corresponde con el área menos soleada, más cercana al dominio humano $y$, además, con la mayor presencia de costra negra de contaminación recubriendo la superficie de la piedra de fábrica (y por tanto con yeso de neoformación bajo ellas), siendo la zona más desfavorable del monumento para la colonización de plantas superiores.
Así pues, toda la fitocenosis está establecida en un rango de altura vertical que va desde los 10 a los $32 \mathrm{mts}$. sobre el nivel de calle (cota $0 \mathrm{mts}$ ).

En la figura 10 se expone el plano que refleja el patrón de distribución de especies en la fachada.

\section{Las plantas de San Pablo vistas como agentes de alteracion}

Como el presente estudio se ha centrado en las plantas vasculares con semillas (espermatofitos ó "plantas superiores"), diremos algo acerca del principal mecanismo de degradación que producen sobre las rocas colonizadas. Este se deriva de la doble acción de sus raíces: una acción puramente mecánica, visible al exterior, y otra exclusivamente química, más oculta y menos perceptible a los ojos del observador.

En el primer caso, las raíces, al crecer, actúan como zapadores que van socavando las juntas y oquedades de la piedra, siendo el caso extremo la fuerza extraordinaria que pueden llegar a ejercer las plantas vasculares leñosas (lignificadas, tipo árbol ó arbusto), alcanzando presiones internas de hasta 15 atmósferas capaces de mover sillares de algunos cientos de kilos.

La segunda acción, la de naturaleza química, puede tener gran trascendencia, puesto que los ápices radicales de las plantas contienen iones Hidrógeno positivo que atacan las partículas carbonatadas del material, aportando también numerosos complejos orgánicos quelantes al substrato.

Además, inducen cambios en el material lapídeo que las alberga, facilitando la entrada de agua saturada de sustancias agresivas al interior del mismo, aumentando significativamente los niveles de humedad de su sistema poroso interno, un hecho verdaderamente crucial en el grado de alteración-degradación de los materiales pétreos ó similares (cerámicos, morteros de cal), pues el agua es el disolvente ó vehículo universal de toda clase de compuestos hidrosolubles potencialmente dañinos para cualquier tipo de material por el que circule libremente, además de provocar daños mecánicos derivados de los ciclos de hielo-deshielo producidos en su interior.

Los biotipos de las plantas que suelen encontrarse en edificios históricos se corresponde, por lo general, con especies fanerógamas (con flores, frutos y semillas) de carácter nitrófilo y ruderal, es decir, plantas pioneras formadoras de suelo, que resisten el período más desfavorable de su ciclo vital en forma de semillas resistentes, por medio de las que se multiplican. Suele tratarse, en la mayoría de los casos, de especies que dispersan sus semillas mediante el viento (anemocoria) ó los animales (zoocoria). 
En el caso que nos ocupa, la acción puramente física de las plantas de San Pablo es de mínima importancia, ya que al ser biotipos herbáceos de ciclo anual sus raíces no se desarrollan apenas en grosor y longitud, careciendo además de lignina, propia de plantas arbustivas y árboles.

Sin embargo, la comunidad descrita presente en la fachada, sí tiene un alto poder de ataque químico, al ser especies con gran contenido de compuestos orgánicos solubles que elevan mucho el $\mathrm{pH}$ del material subyacente: sales de nitrógeno, fósforo y azufre; ácidos orgánicos, y moléculas quelantes que sustraen los metales de las rocas. El ejemplo más nítido de esto último lo representa la vulvaria, abundante por casi toda la obra, y que contiene un verdadero arsenal de compuestos químicos con gran potencial agresivo para la cohesión del material rocoso ó los morteros hidráulicos de unión entre piezas.

Todos estos productos químicos de origen vegetal sirven, además, como perfecto caldo de cultivo para el asentamiento de todo tipo de microorganismos (hongos, cianobacterias ó algas endolíticas, algas verdes, quimiobacterias) que basan su ciclo biológico en las sustancias excretadas por estas especies dentro de la obra pétrea, haciendo aun más agresiva la acción degradante interna de las mismas.

A todo lo dicho hemos de añadir otro dato importante: la piedra de construcción de la fachada (la caliza lacustre de Campaspero) tiene unas características petrológicas adecuadas para la colonización (y posterior efecto de degradación) de las especies vegetales descritas. Esta roca presenta un índice de porosidad abierta del 12\%, una permeabilidad al vapor de agua (higroscopicidad) de grado medio (4\%), y un elevado número de oquedades tanto en superficie como en su interior (vacuidades, coqueras y geodas).

Todo lo expuesto hasta ahora nos hace suponer que, desde el punto de vista de la alteración química, la acción biodegradante de las poblaciones de plantas establecidas pueda tener una importancia relativa. En todo caso, hemos de puntualizar que, por elevado que sea el riesgo potencial de biodeterioro de la comunidad vegetal, su presencia nos sirve, esencialmente, como perfectos indicadores biológicos de otros factores de alteración que afectan el bien cultural, destacando por encima de todos el alto nivel de humedad y sales hidrosolules presentes en el material rocoso. El agua es el vehículo de casi todos los demás agentes de alteración que inciden en la conservación de un bien cultural cualquiera.

También hemos de referirnos al gran problema que se presenciaba en la fachada durante el muestreo, y que no era otro que la enorme cantidad de excrementos de paloma ("palomina") que recubren buena parte del retablo pétreo de San Pablo. La palomina acumulada durante años sobre la piedra, supone una concentración muy elevada de compuestos orgánicos (ácido fosfórico y nitratos sobre todo) que inciden negativamente sobre el material lapídeo, todo lo cuál establece una relación clara de causa-efecto entre el hecho referido y la comunidad vegetal que crece y se desarrolla en el retablo labrado que forma la obra objeto de estudio. Hemos de añadir que a la población sedentaria de palomas que habitan y nidifican todo el año en San Pablo, se les sumaban las parejas de cigüeñas que desde Enero hasta Agosto anidan y crían en las torres (cuerpos de campanas) y pináculos del edificio, y que elevan el nivel de excrementos presentes hasta límites inaceptables desde el punto de vista de la correcta conservación del material pétreo y su correcta apreciación artística y documental.

\section{Conclusiones y recomendaciones acerca del manteni- miento preventivo del monumento}

El análisis final del presente estudio nos permite concluir que la fitocenosis radicada en la fachada está obviamente influenciada por la presencia de una población estable de palomas (y otras aves acompañantes) que desarrollan su ciclo vital anual en buena parte de la misma (básicamente entre el remate superior y la portada principal de la entrada a la iglesia). A causa de ello, la acumulación de guano a lo largo de muchísimos años ha derivado en unas condiciones ideales para la formación de un substrato óptimo para la colonización de las especies que forman la comunidad de plantas vasculares estudiada en éste trabajo.

En cuanto a los aspectos ligados a un adecuado mantenimiento preventivo para evitar la colonización vegetal, una vez acabada la intervención emprendida ahora sobre el $\mathrm{BIC}$, tenemos que apuntar algunas recomendaciones particulares.

Durante los trabajos de restauración se aplicaron tratamientos biocidas destinados a minorizar (la eficacia $100 \%$ de éstos productos es casi nula a medio y largo plazo en ambientes al exterior, como es el caso) el arraigo de organismos sobre la piedra monumental. El producto elegido fué Biotín-T, diluido al 5\% en agua desmineralizada, un biocida de amplio espectro aplicado con brochas y pulverizadores directamente sobre las plantas y los substratos de crecimiento (horizontales y verticales). Una vez muertos los ejemplares se eliminaron manualmente. Posteriormente se inyectaba el producto en los huecos de enraizamiento abiertos al exterior a fin de llegar a los restos de raíces que puedan quedar ocultos en el interior del material.

La aplicación de biocidas (siempre peligrosos para la salud y el medioambiente) ha de hacerla el personal especializado encargado de los trabajos de restauración de la fachada (restauradores profesionales cualificados), empleando todos los medios de protección individual 
(básicamente guantes de nitrilo ó similares y gafas de protección) adecuados a este tipo de sustancias, siguiendo las prescripciones técnicas recomendadas por la empresa fabricante que comercializa el producto, y cumpliendo todos los protocolos de seguridad y salud establecidos en el estudio de prevención de riesgos laborales de la obra.

Lo idóneo es acometer labores periódicas (de tres a cinco años a lo sumo) de conservación preventiva, como la limpieza manual de residuos (orgánicos e inorgánicos) y depósitos en las zonas favorables de acumulación de la obra en su conjunto (cornisas; frontón y albardilla superiores; solado de los campanarios; rincones de labra; etc.), limitando de ésta manera la posibilidad de crear un medio favorable (estrato edáfico fértil) para la germinación de las semillas de las plantas pioneras especializadas en crecer (recordemos que son plantas de ciclo anual ó bianual) en esos medios urbanos degradados. Tras esta intervención previa, se aplicaría de nuevo el tratamiento biocida en esas zonas favorables al arraigo y crecimiento de nuevas plantas.

Con un mantenimiento programado y eficaz, las obras restauradas pueden prolongar su buen estado de conservación durante períodos de tiempo muy amplios, ahorrando con ello recursos y esfuerzos (económicos y humanos) de una manera más racional y beneficiosa, tanto para el patrimonio cultural como para el ciudadano que le admira y disfruta.

\section{Agradecimientos}

El autor quiere agradecer su colaboración a la empresa In Situ SL, responsable de los trabajos específicos de restauración de la fachada de San Pablo.

\section{Bibliografía}

BLÁZQUEZ, A., LORENZO, J., FLORES, M., y GÓMEZ-ALARCÓN, G. (2000): Evaluation of the effect of some biocides against isolated from historic monuments. Aerobiología 16: 423-428.

CANEVA, G. et al. (2000): La Biología en la Restauración. Ed. Nerea S.A.- Junta de Andalucía - Consejería de Cultura. IAPH.

CASTROVIEJO, S. (Coord. general). (1986-2012): Flora ibérica. Real Jardín Botánico de Madrid. CSIC. http://www.floraiberica. es

DÍAZ HERRERO,A., JIMÉNEZ BAILÓN, L., y SANZ REDONDO, R. (2002): Aproximación al catálogo de la flora de monumentos de Segovia. Obra Social Caja de Segovia.

FONT QUER, P. (1990): Plantas medicinales. El Dioscórides renovado. Ed. Labor S.A. 12a edición. Barcelona.
Fundación Caja Madrid (2008): Memoria de la Restauración de la Fachada de San Pablo de Valladolid. http://www.multimedia. fundaciónmontemadrid.es/patrimonio/sanpablo/Resources/ pdf/Memoria.pdf.

GARABITO,J.etal.(2013):Métodosparala limpiezafísica, química y biológica de las fábricas de piedra de monumentos históricos. Rev. Informes de la Construcción. Vol.65, 531, 367-380. http:// www.csic.es/index.php/informesdelaconstruccion/article/ viewFile/2887/3194

GARCÍA, R., y ROSATO, V. G. (2011): Organismos hallados en muros de mampostería de ladrillos. $2^{\circ}$ Congresolberoamericano y X Jornadas "Técnicas de Restauración y Conservación del Patrimonio'. http://www.lemac.frlp.utn.edu.ar/wp_content/ uploads/2011/12/2011_organismos_hallados_en_muros_ de_mampostería_de_ladrillos_2COIBRECOP/pdf

GARCÍA SÁEZ, M. (1994): Biología aplicada a la Conservación del Patrimonio Cultural. Revista Quercus. Cuaderno 102. Madrid.

GÓMEZ-ALARCÓN, G., y SÁIZ-JIMÉNEZ, C. (2013): Biodeterioro de monumentos y biorremediación: estado actual y perspectivas futuras. Anales Real Acad. Farm. Vol 79, № 4 pag.562-579. http://www.anales.ranf.com/2013/vol4/1457.htm

GUILLITTE, O. (1995): Bioreceptivity: a new concept for building ecology studies. Sci. Total Environ. 167: 215-220

HERAS, P., INFANTE, M. Y RENOBALES, G. (2000): La colonización vegetal de la Catedral de Sta. María de Vitoria-Gasteiz. Fundación Sta. María. http://www.catedralvitoria.com

SÁIZ-JIMÉNEZ, C., Y ARIÑO, X. (1995): Colonización biológica y deterioro de morteros por organismos fotótrofos. Rev. Materiales de Construcción, Vol. 45, no 240. CSIC. Madrid. http://www. digital.csic.es/bitstram/10261/78461/1/Colonización\%20 biológica.pdf 


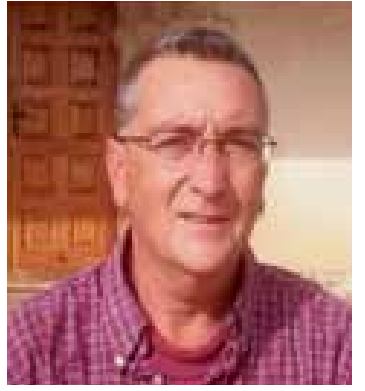

Manuel García Sáez

casadabuti@gmail.com

Licenciado en Biología y Máster en Museología, desde 1987 hasta 2012 ha desarrollado su vida profesional en empresas de conservación y restauración de bienes culturales como especialista en biodeterioro y conservación preventiva, habiendo intervenido en todo tipo de BICs: edificios históricos; artesonados; retablos; musivaria; pinturas murales; restos arqueopaleontológicos ó colecciones museológicas.

Artículo enviado el 09/12/2014

Artículo aceptado el 7/07/2015 